\title{
INFLUENCE OF EXPLOSION CHAMBER SHAPE ON TIMING PARAMETERS OF DISPERSER
}

\author{
Zuzana SZABOVÁ ${ }^{1}$, Richard KURACINA ${ }^{1}$, Miroslav MYNARZ², \\ Marián ŠKVARKA ${ }^{1}$ \\ ${ }^{1}$ Slovak University of TeChNOLOGY In BRATISLAVA, \\ FACULTY OF MATERIALS SCIENCE AND TECHNOLOGY IN TRNAVA, \\ INSTITUTE OF INTEGRATED SAFETY \\ Ulica JÁNA Bottu 2781/25, 91724 TRNAVA, SLOVAK REPUBliC \\ ${ }^{2}$ TECHNICAL UNIVERSITY OF OSTRAVA \\ FACULTY OF SAFETY ENGINEERING \\ LuMírova 630/13, CZ-70030, OSTRAVA, CZECH REPUBLIC \\ e-mail: zuzana.szabova@stuba.sk,richard.kuracina@stuba.sk,miroslav.mynarz@vsb.cz, \\ marian.skvarka@stuba.sk \\ Received 28 April 2021, Accepted 21 May 2021, Published 20 July 2021
}

\begin{abstract}
A standardized device with a volume of $1 \mathrm{~m}^{3}$ or $20 \mathrm{~L}$ is used to determine explosion parameters. An explosion chamber where explosion takes place is of a spherical or cylindrical shape that suits the shape of a cubic container. In the case of a cylindrical vessel, the diameter and depth of the vessel are 1: 1. In this case, it is a spherical vessel with a volume of 365 liters. Time parameters of the disperser in the spherical vessel are compared with those of a truncated spherical vessel with a volume of 291 liters. Comparison of the measurement results showed that the optimal delay time of the explosion chamber with a volume of 291 liters is $290 \mathrm{~ms}$, while the delay time of the explosion chamber with a volume of 365 liters is $350 \mathrm{~ms}$.
\end{abstract}

\section{Keywords}

Explosion chamber, dispersed dust, disperser, timing parameters

\section{INTRODUCTION}

Dust is a by-product of different processes that include dry and powdery material conveying, solids crushing and screening, sanding, trimming of excess material, tank and bin feeding and storing of granular materials, and a number of other processes. Combustible dust explosions resulte in the loss of life, multiple injuries and substantial property and business damage [1]. 
Explosive dust can be produced mainly $[2,3,4,5,6]$ in:

- chemical industry

- food and agricultural industries

- mining industry

- engineering industry

- wood processing industry

- textile industry

- automotive industry, etc.

\section{MATERIALS AND METHODS}

An explosion chamber KV 150M2 was used to determine the timing parameters of the disperser. The chamber consists of a spherical iron shell with an inner diameter of $900 \mathrm{~mm}$. Inside the chamber is an iron plate for damping shock waves. The plate divides the space inside the chamber (Figure 1). Explosion occurs in the upper part of the chamber with a volume of 291 1. Since the lower part of the space in the chamber is separated by an iron plate, the explosion takes place in a container shaped as a truncated sphere with a diameter of $900 \mathrm{~mm}$ and a height of $625 \mathrm{~mm}$.

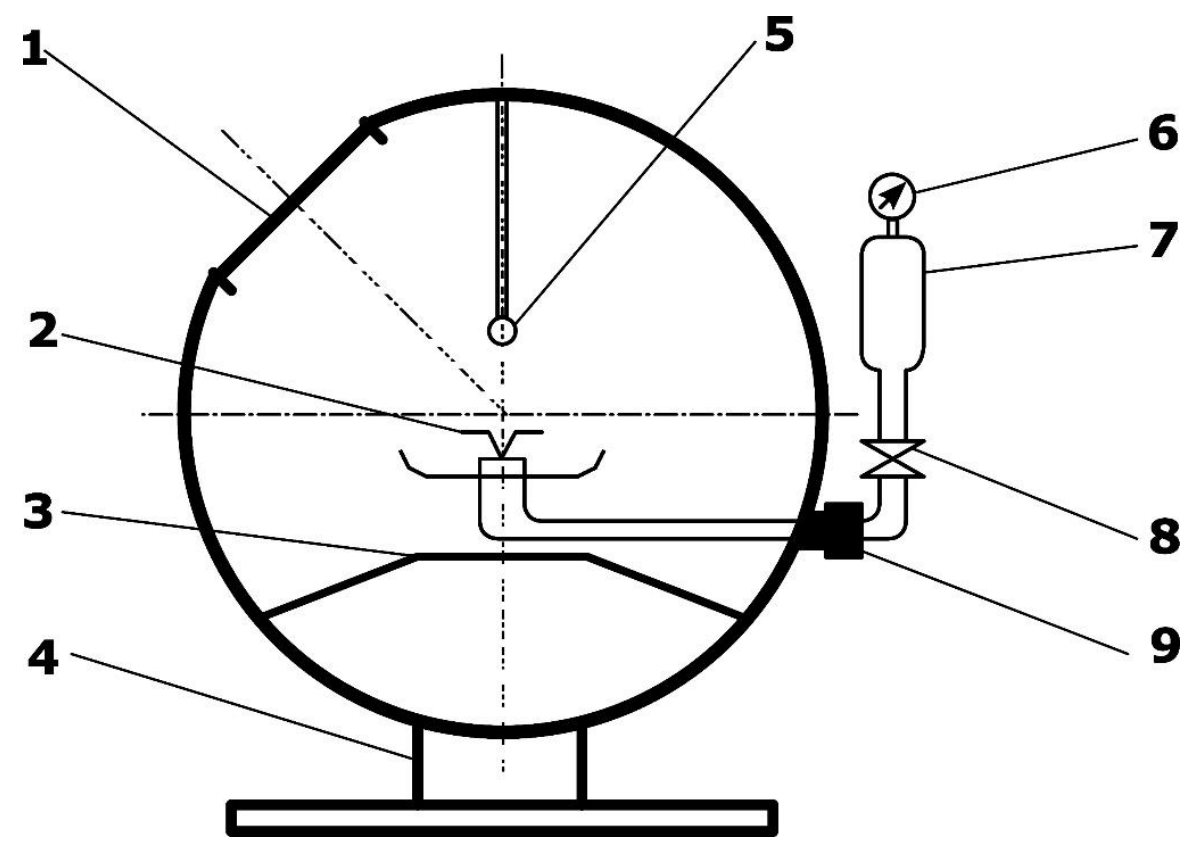

Figure 1 Explosion chamber KV 150M2 (1-chamber cover, 2 - disperser, 3 - shock wave absorbing plate, 4 - stand, 5 - igniter, 6 - manometer, 7 - reservoir of pressurised air, 8 -fast-opening valve, 9 - bushing)

For comparison, timing parameters were also determined in the modified KV $150 \mathrm{M} 2$ chamber, where the iron plate to absorb the shock waves damping was removed (Fig. 2). In such a case, explosion of dispersed dust takes place in a spherical vessel with a diameter of 900 $\mathrm{mm}$ and a volume of 365 liters. 


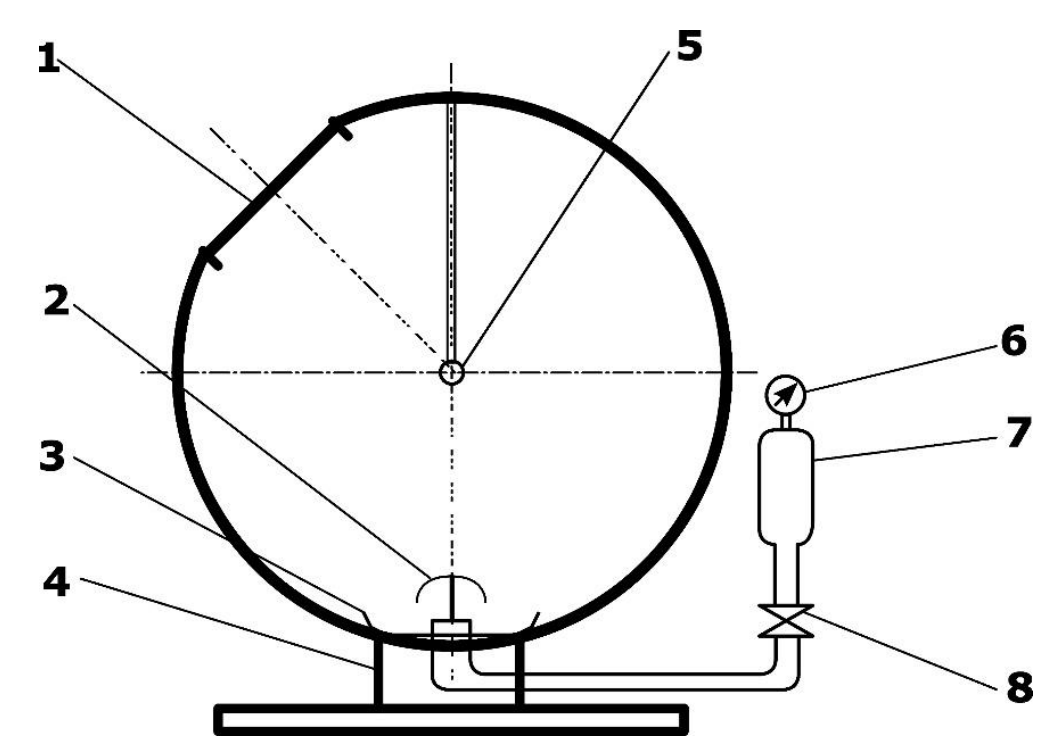

Figure 2 Redesigned explosion chamber KV 150M2 (1 - chamber cover, 2 - disperser, 3 - dispersing plate, 4 - stand, 5 - igniter, 6 - manometer, 7 - reservoir of pressurised air, 8 -fast-opening valve)

A nitrocellulose igniter was used to ignite the dispersed dust inside the chamber. Ignition of nitrocellulose was provided by a resistance wire (in a chamber with a volume of $291 \mathrm{~L}$ ) with the igniter activation time of $30 \mathrm{~ms}$ [7] or a pyrotechnic fuse head with an igniter activation time of $29 \mathrm{~ms}$.

The same dust dispersing system was used for dispersion of dust in the explosion chamber. The dispersing system consists of a supply pipe (for compressed air) and a dispersing element - a dispersion plate. Compressed air is supplied to the chamber from a reservoir of pressurised air with a volume of $7.5 \mathrm{~L}$ and a pressure of $10 \mathrm{bar}$.

The time delay value is independent of the sample and its granulometry, and therefore the granulometric composition of the samples is not reported. A starch sample with a concentration of $150 \mathrm{~g} . \mathrm{m}^{-3}$ was used to determine the delay of ignitor activation in the $291 \mathrm{~L}$ chamber (Table 1), and a lycopodium with a concentration of $250 \mathrm{~g} \cdot \mathrm{m}^{-3}$ was used in the $365 \mathrm{~L}$ chamber (Table 2). The measurement was performed according to the STN EN 14004 Standard [8].

\section{RESULTS AND DISCUSION}

The measured values of explosion pressure $\mathrm{P}_{\max }$ and rate of pressure rise are listed in Table 1 for the 291L chamber and Table 2 for the $365 \mathrm{~L}$ chamber.

Table 1 Explosion characteristics of starch sample with concentration of $150 \mathrm{~g} \cdot \mathrm{m}^{-3}$ in $291 \mathrm{~L}$ chamber

\begin{tabular}{|c|c|c|}
\hline Delay time [ms] & $\begin{array}{c}\text { Maximum overpressure } \\
P_{\max }[\mathrm{bar}]\end{array}$ & $\begin{array}{l}\text { Maximum rate of pressure } \\
\text { rise } d P / d t_{\text {max }}\left[\text { bar. }^{-1}{ }^{-1}\right]\end{array}$ \\
\hline 270 & 3.71 & 21.6 \\
\hline 280 & 3.52 & 19.6 \\
\hline 290 & 3.91 & 22.0 \\
\hline 300 & 3.67 & 16.2 \\
\hline 310 & 2.88 & 9.6 \\
\hline 340 & 3.71 & 19.2 \\
\hline
\end{tabular}


Table 2 Explosion characteristics of lycopodium sample with concentration of $250 \mathrm{~g} . \mathrm{m}^{-3}$ in $291 \mathrm{~L}$ chamber

\begin{tabular}{|c|c|c|}
\hline Delay time [ms] & $\begin{array}{c}\text { Maximum overpressure } \\
\boldsymbol{P}_{\max }[\mathbf{b a r}]\end{array}$ & $\begin{array}{c}\text { Maximum rate of pressure } \\
\text { rise } \boldsymbol{d P}_{\boldsymbol{d}} \boldsymbol{d t}_{\text {max }}\left[\mathrm{bar} \mathbf{s}^{-1} \text { ] }\right.\end{array}$ \\
\hline 330 & 6.71 & 103.1 \\
\hline 340 & 6.84 & 112.6 \\
\hline $\mathbf{3 5 0}$ & $\mathbf{6 . 9 1}$ & $\mathbf{1 3 5 . 7}$ \\
\hline 360 & 6.85 & 123.0 \\
\hline 370 & 6.70 & 109.7 \\
\hline 380 & 6.77 & 125.5 \\
\hline 390 & 6.58 & 100.4 \\
\hline
\end{tabular}

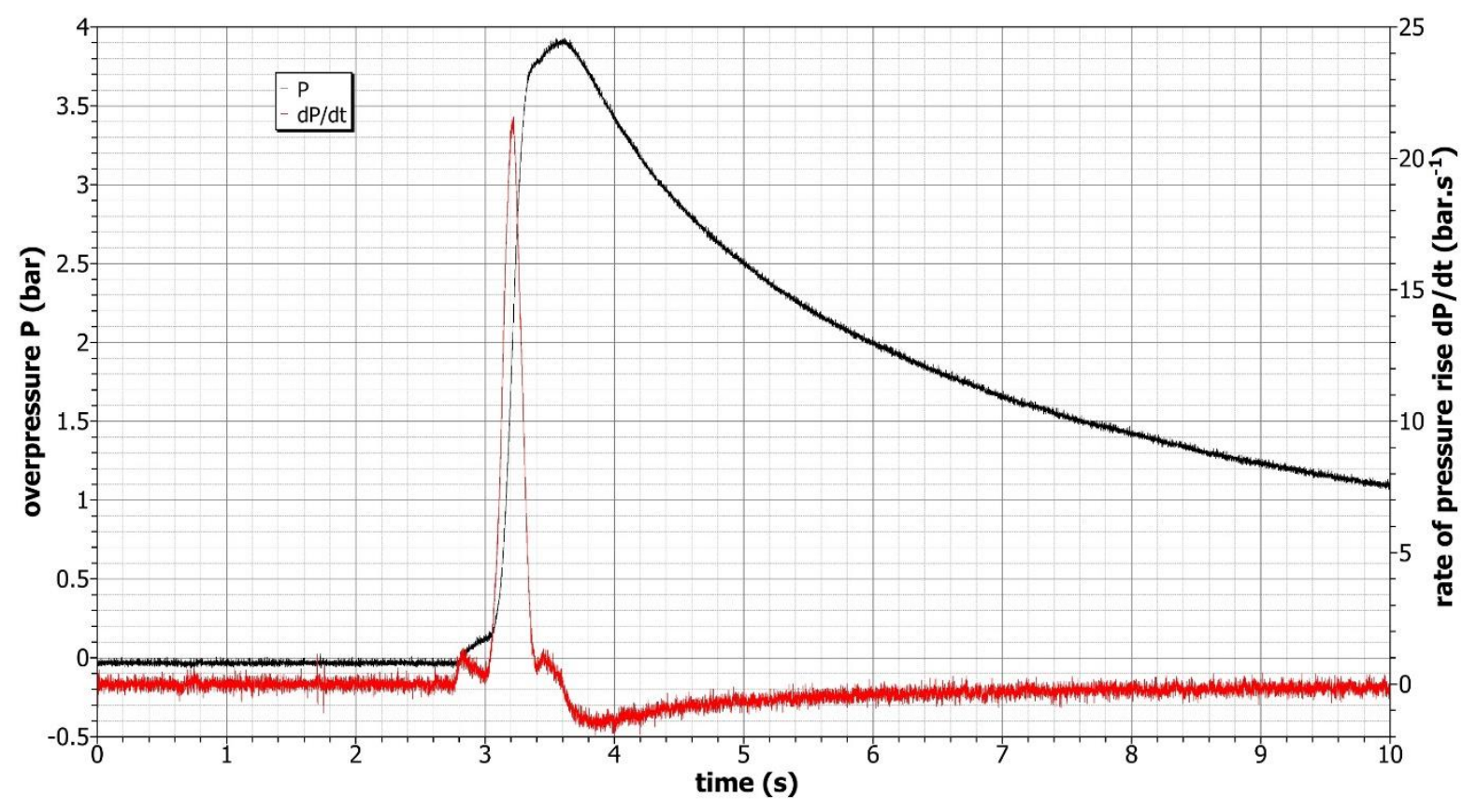

Figure 3 Explosion pressure $P$ and rate of explosion pressure rise $d P / d t$ of starch sample with concentration of 150 g.m in $291 \mathrm{~L}$ chamber and igniter activation delay $290 \mathrm{~ms}$ 


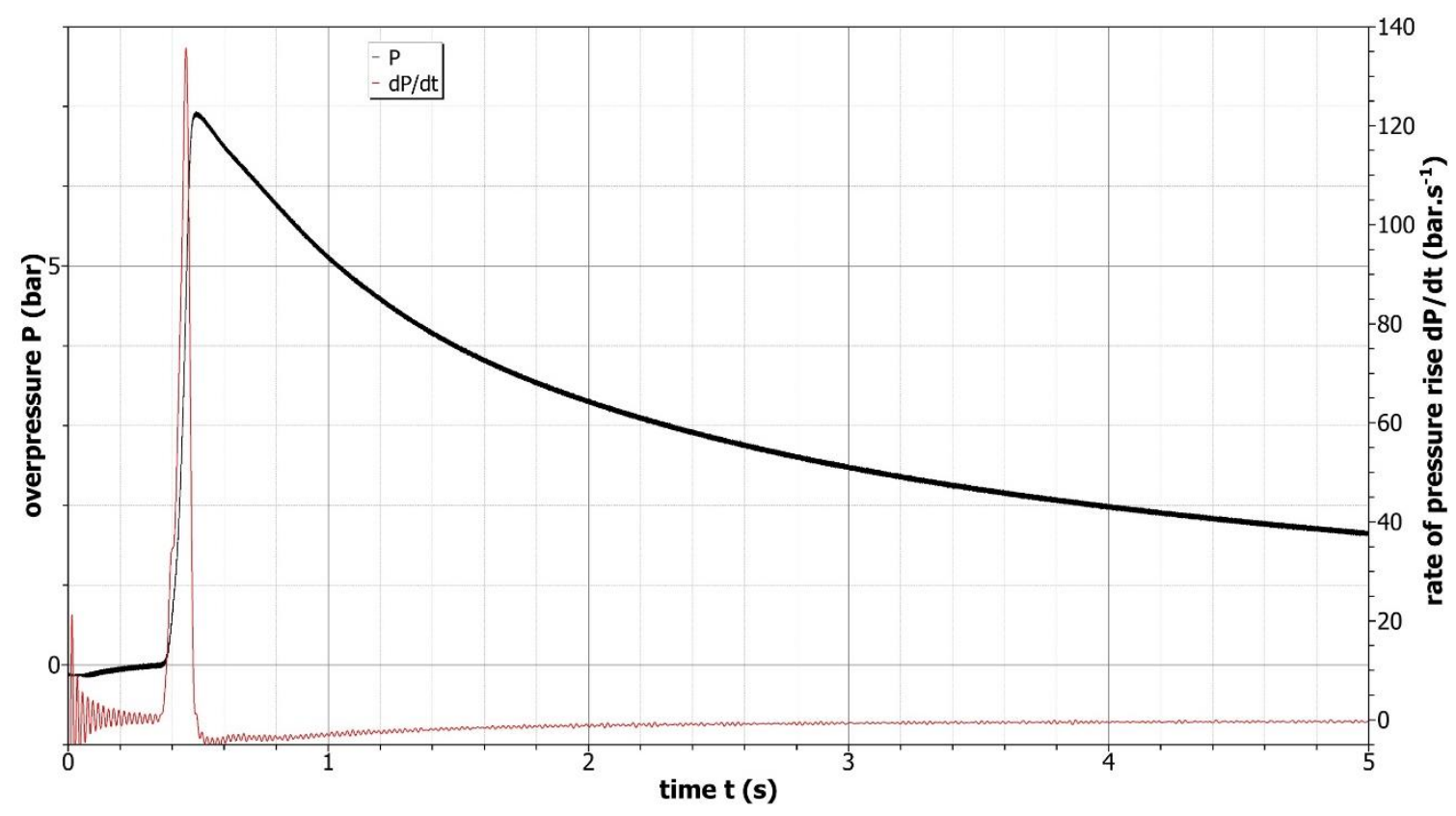

Figure 4 Explosion pressure $P$ and rate of explosion pressure rise dP/dt of lycopodium sample with concentration of $150 \mathrm{~g} . \mathrm{m}^{-3}$ in $291 \mathrm{~L}$ chamber and igniter activation delay $350 \mathrm{~ms}$

The measured values show that the highest value of explosion pressure and rate of pressure rise in the $291 \mathrm{~L}$ chamber was reached at the igniter activation delay value of $290 \mathrm{~ms}$, as shown in Figure 3. In the $365 \mathrm{~L}$ chamber, the highest values of explosion parameters were reached at the igniter activation delay value of $350 \mathrm{~ms}$, as illustrated in Figure 4.

The time delay of ignitor activation after dispersing the sample is an important factor in measuring the explosion characteristics. The delay is affected by the shape and size of the vessel in which the explosion occurs. As the volume of the vessel increases, the optimal delay time increases, too. A comparison of the delay time from the characteristic dimension of the vessel (equivalent diameter) with the standardized values $\left(60 \mathrm{~ms}\right.$ in $20 \mathrm{~L}$ sphere and $600 \mathrm{~ms}$ in $1 \mathrm{~m}^{3}$ chamber) is shown in Figure 5. Figure 5 also indicates that the value of the igniter activation delay is directly proportional to the equivalent chamber diameter.

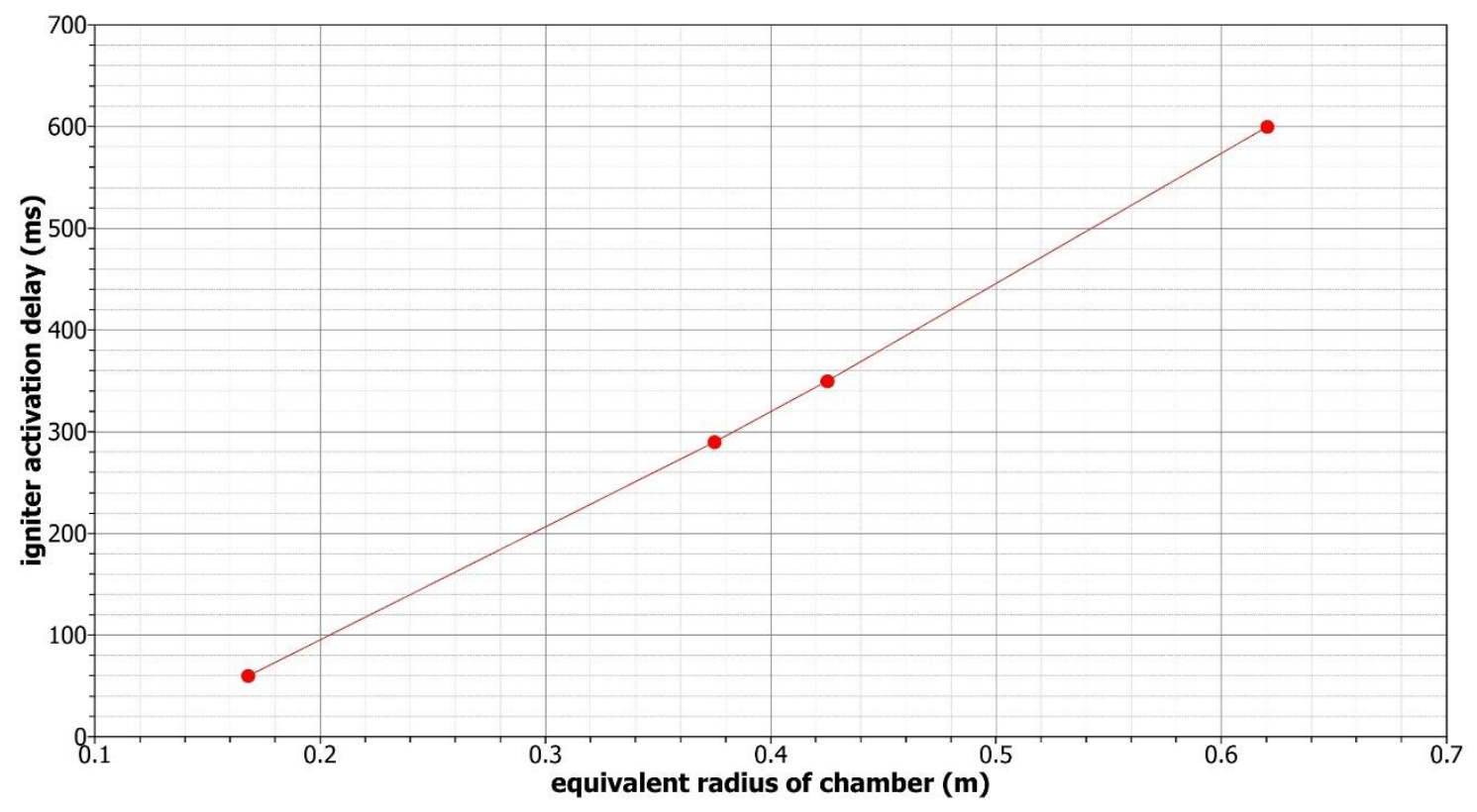

Figure 5 Igniter activation delay time versus the equivalent radius of the chamber 


\section{CONCLUSION}

The time delay for activating the igniter depends on the size the volume of the chamber where the explosion of the dispersed dust takes place. For explosion chambers with a volume of $20 \mathrm{~L}$ and $1 \mathrm{~m} 3$, the delay value is specified in EN 14034 Standard. Based on the measurements, it can be concluded that the value of the igniter delay is $290 \mathrm{~ms}$ for the $291 \mathrm{~L}$ chamber, and $350 \mathrm{~ms}$ for the $365 \mathrm{~L}$ chamber. The value of the delay is directly proportional to the characteristic dimension of the chamber, which is the inner diameter.

Further measurements will be focused on monitoring the time parameters of various types of igniters which can be used to study of explosion parameters of dispersed dusts.

\section{Acknowledgement}

The research was supported by the KEGA Project 016STU-4/2021 and KEGA Project 020STU$4 / 2021$.

\section{References}

[1] CHEREMISINOFF, N. P. 2014. Dust Explosion and Fire Prevention Handbook. A Guide to Good Industry Practices. Scrivener Publishing Wiley, 352 p. ISBN 978-1-118-77350-5

[2] ECKHOFF R. K. 2009. Understanding dust explosions. The role of powder science and technology. Journal of Loss Prevention in the Process Industries, 22, pp. 105-116

[3] ECKHOFF R.K. 2003. Dust explosions in the process industries. Gulf Professional Publishing, 719 p. ISBN 3669780750676021

[4] MARMO L., FERRI A., DANZI E. 2019. Dust Explosion hazard in the textile industry. Journal of Loss Prevention in the Process Industries, 62, art. 103935

[5] ECKHOFF, R. K. 2009. Understanding dust explosions. the role of powder science and technology. J. Loss Prev. Process Ind., 22:105 - 116.

[6] TASCÓN, A., RUIZ, A., and AGUADO, P. 2011. Dust explosions in vented silos: Simulations and comparisons with current standards. Powder Technol., 208:717 - 724.

[7] KURACINA R., SZABOVÁ Z., PASTIER M., MENČÍK M. 2017. Determination of the Rate of Ignition of Nitrocellulose by Resistance Wire for the Igniter of KV 150 M2, Central European Journal of Energetic Materials, 14(2), pp. $461-468$.

[8] EN 14034-3+A1:2011-08. 2011. En 14034-3+a1:2011-08. determination of explosion characteristics of dust clouds. part 3: Determination of the lower explosion limit LEL of dust clouds.

\section{ORCID}

Zuzana Szabová $\quad$ 0000-0002-7886-1623

Richard Kuracina $\quad$ 0000-0003-1468-0820 